\title{
Voltammetric determination of vildagliptin in a pharmaceutical formulation
}

\author{
Muneer Fadr, Abdulaziz Nabil Amro*, Sami Ben Aoun \\ Chemistry Department, Faculty of Science, Taibah University, Al-Madinah Al-Munwwarah, Kingdom of Saudi Arabia \\ *For correspondence: Email: abdulazizamro@yahoo.com
}

Sent for review: 25 May 2018

Revised accepted: 27 August 2018

\begin{abstract}
Purpose: To determine vildagliptin concentration in a pharmaceutical formulation using voltammetric analysis techniques, and optimize the parameters affecting the techniques.

Method: Four types of voltammetry techniques, including cyclic voltammetry (CV), differential pulse voltammetry (DPV), square wave voltammetry (SWV), and linear sweep voltammetry (LSV), were employed to measure vildagliptin. Platinum (Pt) and glassy carbon (GC) were used as working electrodes, while $\mathrm{KNO}_{3}(1 \mathrm{M})$ and phosphate buffer $\left(\mathrm{NaH}_{2} \mathrm{PO}_{4} / \mathrm{H}_{3} \mathrm{PO}_{4}\right) \mathrm{pH} 6.8$ were used to study optimal voltammetric analysis conditions.

Results: CV results indicate that vildagliptin is electroactive and exhibits irreversible redox cycles while LSV results showed an oxidation peak current around $1.35 \mathrm{~V}$ that has high sensitivity and a linear standard regression line correlation coefficient of 0.9995. In addition, LSV results showed that vildagliptin has a lower limit of detection of $\sim 0.241 \mathrm{mM}$ and a limit of quantification of $0.802 \mathrm{mM}$. Finally, the results show that vildagliptin has an acceptable level of recovery of $104.1 \%$ and a relative standard deviation of $0.52 \%$ for the commercially available vildagliptin tablets used in this study.

Conclusion: The accuracy and precision of all applied voltammetric techniques for vildagliptin analysis are within accepted limits stipulated in pharmaceutical analysis quality control guidelines. The recommended method for vildagliptin analysis is LSV with Pt as the working electrode and KNO3 (1 M) as the supporting electrolyte.
\end{abstract}

Keywords: Vildagliptin, Cyclic voltammetry, Square wave voltammetry, Differential pulse voltammetry, Linear sweep voltammetry

\footnotetext{
This is an Open Access article that uses a funding model which does not charge readers or their institutions for access and distributed under the terms of the Creative Commons Attribution License (http://creativecommons.org/licenses/by/4.0) and the Budapest Open Access Initiative (http://www.budapestopenaccessinitiative.org/read), which permit unrestricted use, distribution, and reproduction in any medium, provided the original work is properly credited.

Tropical Journal of Pharmaceutical Research is indexed by Science Citation Index (SciSearch), Scopus, International Pharmaceutical Abstract, Chemical Abstracts, Embase, Index Copernicus, EBSCO, African Index Medicus, JournalSeek, Journal Citation Reports/Science Edition, Directory of Open Access Journals (DOAJ), African Journal Online, Bioline International, Open-J-Gate and Pharmacy Abstracts
}

\section{INTRODUCTION}

Chromatography, electrochemistry considered the most commonly used methods in pharmaceutical analyses [1]. Electroanalytical chemistry has been a fundamental branch of analytical chemistry since the beginning of the nineteenth century [2]. Recently, voltammetric analysis has become the most common electroanalytical method used in environmental research, chemical monitoring laboratories, and quality control units of several industries, biological and clinical laboratories [3]. Voltammetric analysis has many advantages such as simplicity, moderate instrumentation and 
running costs, and instrument portability that make it a better alternative to chromatographic and spectroscopic techniques.

About two-thirds of the world population suffers from type 2 diabetes mellitus (T2DM), and this is expected to increase [4]. Vildagliptin is a relatively new oral antidiabetic agent and a member of a new class of orally active antidiabetic drugs called glyptins. [5,6]. These drugs also have positive cardiovascular and antiinflammatory effects $[5,7,8]$. Vildagliptin is a good inhibitor of dipeptidyl peptidase-4 enzyme DPP-4 $\left(\mathrm{IC}_{50}=3.5-34 \mathrm{nM}\right.$; Figure 1) $[9,10]$.

Previous chromatographic assessments of vildagliptin include reversed-phase high performance liquid chromatography (RP-HPLC) analysis of different matrices, such as bulk and tablet dosage forms [11-14]. Hydrophilic interaction liquid chromatography tandem mass spectrometry (HILIC-MS/MS) developed and validated for the determination of vildagliptin in human plasma [15]. Bratty et al developed a liquid chromatography (LC)-MS/MS method for the simultaneous determination of gliptins in human plasma. [16] Spectrophotometric methods to assess vildagliptin in bulk and pharmaceutical dosage forms have also been used [17-21].

In this study, we choose to use more accurate electrochemical voltammetric analysis technique for the determination of vildagliptin in a pharmaceutical formulation. The experimental parameters affecting the used technique, such as types of working electrodes and supporting electrolytes, were optimized.

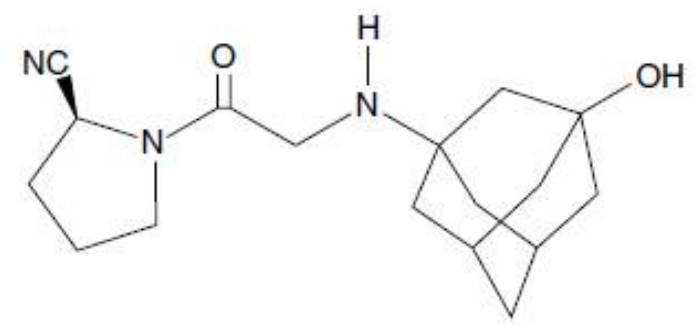

Figure 1: Chemical structure of vildagliptin

\section{EXPERIMENTAL}

\section{Materials and reagents}

The standard pharmaceutical formulation (pure powder) of vildagliptin was obtained from CAD Pharmaceuticals (Saudi Arabia). Commercially available tablets of vildagliptin Gulvus ${ }^{\text {TM }}$ (50 mg) were obtained from Novartis (Saudi Arabia). Standard Stock solutions of $10 \mathrm{mM}$ were prepared from pure vildagliptin powder;
Supporting electrolytes were used to prepare standard stock solutions and dilute the stock solutions to prepare the working standard solutions.

Gulvus $^{\mathrm{TM}}$ tablets were weighed and ground by mortar and pestle, and then a certain mass was dissolved in the supporting electrolyte solution. Next, the solution was filtered using simple filtration to remove undissolved substance. The filter used in the filtration was washed several times with supporting electrolytes, and the solution volume was completed to the mark with supporting electrolyte. The phosphate buffer supporting electrolyte solution was prepared by dissolving $24 \mathrm{~g}$ of $\mathrm{NaH}_{2} \mathrm{PO}_{4} \cdot \mathrm{H}_{2} \mathrm{O}$ in $800 \mathrm{ml}$ of deionized water, adding $85 \% \mathrm{H}_{3} \mathrm{PO}_{4}$ until a $\mathrm{pH}$ of 6.8 was reached and making up the solution to $1 \mathrm{~L}$ with deionized water. Potassium nitrate $\left(\mathrm{KNO}_{3}, \mathrm{ACS}\right.$ reagent grade; Fluka) was used for the preparation of supporting electrolyte. Milli-Q water was used to prepare all samples and supporting electrolytes. Stock standard solutions were prepared by dissolving solid vildagliptin in supporting electrolyte solutions. Supporting electrolytes were also used to dilute the stock solution to prepare the working standard solutions.

\section{Apparatus}

All electrochemical measurements were made using a PGSTAT 204 potentiostat from Metrohm Autolab. All measurements were made using a three - electrodes system; a glassy carbon (GC) or platinum $(\mathrm{Pt})$ working electrode, $\mathrm{Ag} / \mathrm{AgCl}$ reference electrode, and a $\mathrm{Pt}$ sheet auxiliary electrode.

\section{Statistical analysis methods}

All voltammetric analysis data have been processed by Microsoft excel software. All experimental parameters were done in triplicates. Standard calibration curves of concentration versus anodic peak current and statistical analysis have been done by Microsoft excel software.

Limit of detection was taken as the analyte concentration giving a signal equal to the blank signal, $\mathrm{Y}_{\mathrm{B}}$, plus three standard deviations of the blank, $\mathrm{S}_{\mathrm{B}}$

Limit of detection $=Y_{B}+3 S_{B}$

Limit of quantifiction was computed as in Eq 2.

Limit of quantitation $=Y_{B}+10 S_{B}$ 
Relative standard deviation (RSD) was obtained as in Eq 3.

$\mathrm{RSD}=100 * \mathrm{~S} / X$

where $S$ is standard deviation, and $X$ is the mean.

\section{RESULTS}

\section{Cyclic voltammetry}

Cyclic voltammetry was used to study the electroactivity of pure vildagliptin. Glassy carbon and Pt electrodes were applied, and $1 \mathrm{M} \mathrm{KNO}_{3}$ and phosphate buffer were used as supporting electrolytes (Figure 2). Voltammograms show that vildagliptin was electroactive with an irreversible redox cycle and anodic peak current in the range of $1.25-1.45 \mathrm{~V}$ when $\mathrm{Pt}$ was used as the working electrode and $\mathrm{KNO}_{3}$ was used as the supporting electrolyte. When a GC electrode was used, anodic peaks of 1.15 and $1.25 \mathrm{~V}$ were evident for $\mathrm{KNO}_{3}$ and phosphate buffer supporting electrolytes, respectively (Figure 2). When phosphate buffer was used with $\mathrm{Pt}$ as the working electrode, the voltammograms showed erratic results (not shown). According to the voltammograms in Figure 2, the $\mathrm{Pt}$ electrode showed sharper anodic peaks than the GC electrode. Furthermore, high correlation coefficients were exhibited for all calibration curves of vildagliptin $(2-10 \mathrm{mM})$ determined by cyclic voltammetry (Figure 2 and Table 1).

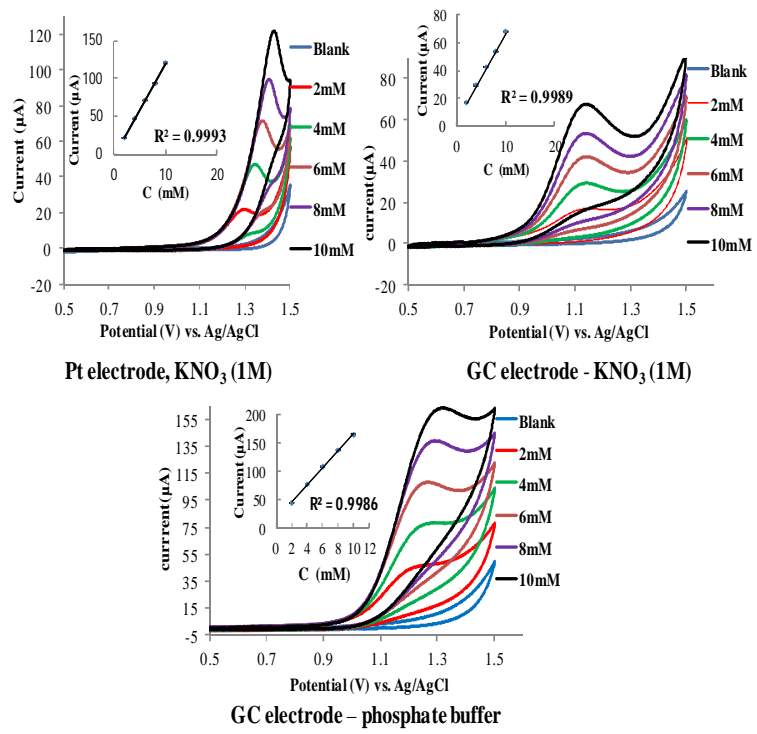

Figure 2: Cyclic Voltammetry of pure vildagliptin (2 $10 \mathrm{mM}$ ) using $\mathrm{Pt}$ and $\mathrm{GC}$ electrodes, with phosphate buffer $\mathrm{pH} 6.8$ and $1 \mathrm{M} \mathrm{KNO}_{3}$ supporting electrolytes, scan rate of $0.1 \mathrm{~V} / \mathrm{s}$. Triplicate determinations of all concentrations
Differential pulse voltammetry (DPV) and square wave voltammetry (SWV)

Use of a Pt working electrode with $\mathrm{KNO}_{3}$ supporting electrolyte showed a sharper peak than that of GC electrode for both DPV and SWV methods (Figure 3 and Figure 4, respectively). On the other hand, using $\mathrm{KNO}_{3}$ as supporting electrolyte gave a better correlation coefficient than phosphate buffer (Figure 3 and Figure 4, respectively). The anodic peak potential shifts to higher values as pure vildagliptin concentration increases when $\mathrm{Pt}$ is used as working electrode in both DPV and SWV methods (Figure 3 and Figure 4, respectively).

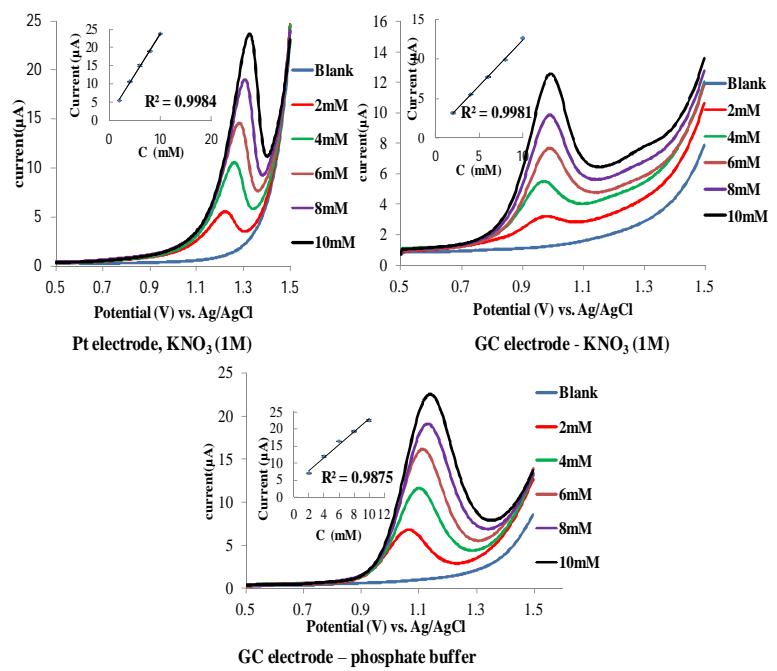

Figure 3: DPV of pure vildagliptin $(2-10 \mathrm{mM})$ using $\mathrm{Pt}$ and GC electrodes, with phosphate buffer $\mathrm{pH} 6.8$ and $1 \mathrm{M} \mathrm{KNO}_{3}$ supporting electrolytes. Triplicate determination was made at all concentrations

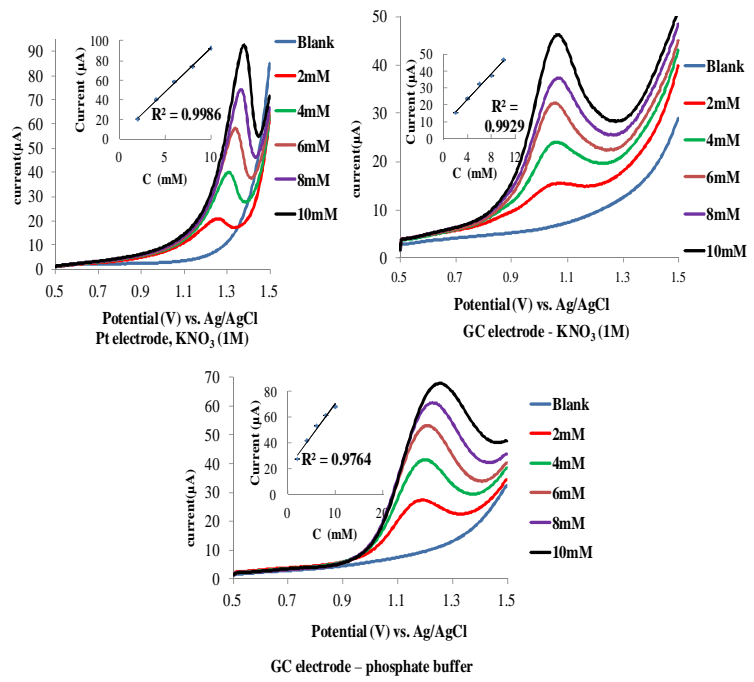

Figure 4: SWV of pure vildagliptin (2-10 mM) using $\mathrm{Pt}$ and $\mathrm{GC}$ electrodes, with phosphate buffer $\mathrm{pH} 6.8$ and $1 \mathrm{M} \mathrm{KNO}_{3}$ supporting electrolytes. Triplicate determinations of all concentrations. 


\section{Linear sweep voltammetry (LSV)}

Linear sweep voltammetry showed the highest peak currents and correlation coefficients compared with results of all previously mentioned methods for pure vildagliptin analysis (Figure 5). In the optimization of electrode and supporting electrolyte, all voltammograms showed good results. The best conditions for determination of vildagliptin included a Pt working electrode with $\mathrm{KNO}_{3}$ as supporting electrolyte (Figure 5).

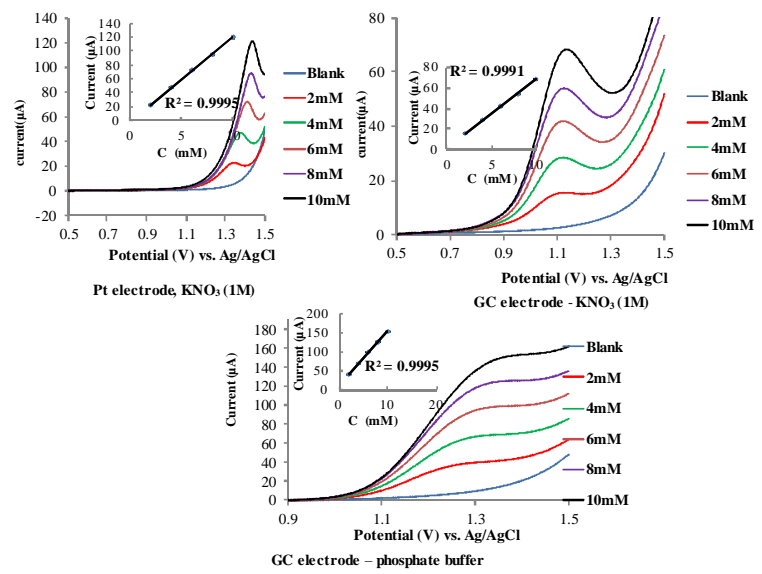

Figure 5: LSV of pure vildagliptin $(2-10 \mathrm{mM})$ using $\mathrm{Pt}$ and GC electrodes, with phosphate buffer $\mathrm{pH} 6.8$ and $1 \mathrm{M} \mathrm{KNO}_{3}$ supporting electrolytes. Triplicate determinations of all concentrations

\section{DISCUSSION}

A comparison of correlation coefficient $\left(R^{2}\right)$, limit of detection (LOD), and limit of quantitation (LOQ) between Pt and GC electrodes used in all applied voltammetric methods in this study is shown in Table 1 . Only the $\mathrm{KNO}_{3}$ supporting electrolyte results are shown in this table because they were better than the phosphate buffer results in all voltammetric methods (as discussed earlier). According to the results in Table 1, it can be concluded that the LSV method with $\mathrm{Pt}$ working electrode was the optimal combination for vildagliptin analysis because it has the lowest LOD and LOQ and the highest sensitivity.

The concentration, recovery, and relative standard deviation (RSD) results of four voltammetric methods (CV, DPV, SWV, and LSV) using a $4 \mathrm{mM}$ solution of commercially available vildagliptin (Gulvus ${ }^{\mathrm{TM}}$ ) are shown in Table 2.

Table 1: Linearity of pure vildagliptin standard solution (range $2-10 \mathrm{mM}, \mathrm{KNO}_{3} 1 \mathrm{M}$ )

\begin{tabular}{lcccc}
\hline Method & LR & $\mathbf{R}^{2}$ & LOD $(\mathbf{m M})$ & LOQ $(\mathbf{m M})$ \\
\hline CV (GC Electrode) & $\mathrm{y}=6.312 \mathrm{x}+4.5012$ & 0.9989 & 0.366 & 1.221 \\
CV (Pt Electrode) & $\mathrm{y}=12.209 \mathrm{x}-2.060$ & 0.9993 & 0.281 & 0.939 \\
DPV (GC Electrode) & $\mathrm{y}=1.167 \mathrm{x}+0.7451$ & 0.9981 & 0.473 & 1.576 \\
DPV (Pt Electrode) & $\mathrm{y}=2.2417 \mathrm{x}+1.312$ & 0.9984 & 0.431 & 1.439 \\
SWV (GC Electrode) & $\mathrm{y}=3.7915 \mathrm{x}+8.305$ & 0.9929 & 0.823 & 2.011 \\
SWV (Pt Electrode) & $\mathrm{y}=8.864 \mathrm{x}+3.9411$ & 0.9986 & 0.411 & 1.370 \\
LSV (GC Electrode) & $\mathrm{y}=6.527 \mathrm{x}+2.5213$ & 0.9991 & 0.320 & 1.069 \\
LSV (Pt Electrode) & $\mathrm{y}=12.16 \mathrm{x}-1.4499$ & 0.9995 & 0.241 & 0.802 \\
\hline
\end{tabular}

LR: Linear regression, $\mathbf{R}^{2}$ : correlation coefficient, LOD: limit of detection, LOQ: limit of quantification

Table 2: Accuracy and precision of commercial preparation of Gulvus (vildagliptin $50 \mathrm{mg}$ )

\begin{tabular}{|c|c|c|c|c|}
\hline Method & $\begin{array}{l}\text { Gulvus } \\
\text { commercial } \\
\text { preparation }\end{array}$ & $\begin{array}{c}\text { Statistical } \\
\text { parameters }\end{array}$ & $\begin{array}{l}\text { Pt electrode } \\
\left(\mathrm{KNO}_{3}\right)\end{array}$ & $\begin{array}{c}\text { GC electrode } \\
\left(\mathrm{KNO}_{3}\right)\end{array}$ \\
\hline & & Found \pm SD & $4.17 \pm 0.003$ & $4.20 \pm 0.025$ \\
\hline \multirow[t]{3}{*}{ CV } & $4 \mathrm{mM}$ & Recovery\% & 104.2 & 104.93 \\
\hline & & RSD\% & 0.07 & 0.61 \\
\hline & & Found $\pm S D$ & $3.67 \pm 0.007$ & $3.88 \pm 0.036$ \\
\hline \multirow[t]{3}{*}{ DPV } & $4 \mathrm{mM}$ & Recovery \% & 91.65 & 97.02 \\
\hline & & RSD \% & 0.19 & 0.92 \\
\hline & & Found $\pm S D$ & $4.28 \pm 0.03$ & $4.42 \pm 0.007$ \\
\hline \multirow[t]{3}{*}{ SWV } & $4 \mathrm{mM}$ & Recovery \% & 106.9 & 110.5 \\
\hline & & RSD\% & 0.80 & 0.16 \\
\hline & & Found $\pm S D$ & $4.16 \pm 0.02$ & $4.46 \pm 0.018$ \\
\hline \multirow[t]{2}{*}{ LSV } & $4 \mathrm{mM}$ & Recovery\% & 104.1 & 111.6 \\
\hline & & RSD\% & 0.52 & 0.41 \\
\hline
\end{tabular}

SD: standard deviation of triplicate determinations, RSD: relative standard deviation, Recovery = found/added *100 
According to these results, LSV and CV showed better recovery than other methods when a $\mathrm{Pt}$ electrode was used. On other hand, CV and DPV showed better recovery than other methods when a GC electrode was used. The RSD results of all methods were good and within the accepted limits, which reflects the high precision of voltammetric determination of vildagliptin.

\section{CONCLUSION}

Voltammetric analysis indicates that vildagliptin is electroactive with an irreversible redox reaction. All voltammetric results show that vildagliptin is within the accepted limits. Thus, voltammetric analysis is suitable for the determination of vildagliptin in pharmaceutical formulation. However, LSV displayed the best accuracy, precision, recovery, LOD and LOQ of all the voltammetric methods.

\section{DECLARATIONS}

\section{Conflict of Interest}

No conflict of interest associated with this work.

\section{Contribution of Authors}

The authors declare that this work was done by the authors named in this manuscript and all liabilities regarding the content of this article will be borne by them. Muneer Fadr did experimental part supervised by Abdulaziz Nabil Amro and Sami Ben Aoun.

\section{REFERENCES}

1. Siddiqui MR, Alothman ZA, Rahman N. Analytical techniques in pharmaceutical analysis: A review. Arab J Chem 2017; 10: s1409-s 1421

2. Gupta VK, Jain R, Radhapyari K, Jadon N, Agarwal S. Voltammetric techniques for the assay of pharmaceuticals-A review. Anal Biochem 2011; 408: 179-196

3. Barek J, Fogg AG, Muck A, Zima J. Polarography and Voltammetry at Mercury Electrodes. Crit Rev Anal Chem 2001; 31(4): 291-309.

4. Attimarad $M$, Nagaraja $S H$, Aldhubiab BE, Nair $A B$, Venugopala $K N$. Determination of vildagliptin in rat plasma by capillary electrophoresis tandem mass spectrometry: It's application to pharmacokinetic study. Indian J Pharm Educ Res 2017; 51(4): 636-643

5. Scheen AJ. Cardiovascular effects of gliptins. Nat Rev Cardiol 2013; 10 (2): 73-84.

6. Nair AB, Kumria R, Al-Dhubiab BE, Attimarad M, Harsha S. Transdermal delivery of Vildagliptin. Indian $J$ Pharm Educ Res 2016; 50(1): 130-137.
7. Doupis J, Veves A. DDP4 inhibitors, a new approach in diabetes treatment, Adv Ther 2008; 25(7): 627-643.

8. Strain WD, Lukashevich, V, Kothny W, Hoellinger MJ, Paldánius PM. Individualised treatment targets for elderly patients with type 2 diabetes using vildagliptin add-on or lone therapy (INTERVAL): a 24 week, randomized, double-blind, placebo-controlled study. Lancet 2013; 382(9890): 409-416

9. Parmee ER, He J, Mastracchio A, Edmondson $S D$, Colwell L, Eiermann $G$, et al. 4-Amino cyclohexylglycine analogues as potent dipeptidyl peptidase IV inhibitors. Bioorg Med Chem Lett 2004; 14(1): 43-46.

10. Ikuma $Y$, Hochigai $H$, Kimura $H$, Nunami $N$, Kobayashi $T$, Uchiyama $K$, et al. Discovery of 3H-imidazo[4,5clquinolin-4(5H)-ones as potent and selective dipeptidyl peptidase IV (DPP-4) inhibitors. Bioorg Med Chem 2012; 20(19): 5864-5883.

11. Boovizhikannan $T$, Palanirajan VK. RP-HPLC determination of vildagliptin in pure and in tablet formulation. J Pharm Res 2013; 7(1): 113-116.

12. Hanumantha RK, Lakshmana RA, Chandra Sekhar KB. Development and Validation of HPLC Method for the Estimation of Vildagliptin in Pharmaceutical Dosage Form. Int J Pharm Chem Biol Sci 2014; 4(2): 361-366.

13. Kashid AM, Ghorpade DA, Toranmal PP, Dhawale SC. Development and validation of reversed phase HPLC method for the determination of vildagliptin using an experimental design. J Anal Chem 2015; 70(4): 510515.

14. Sultana R, Bachar SC, Rahman F. Development and validation of stability indicating assay method of vildagliptin in bulk and tablet dosage form by RP-HPLC. Int J Pharm Life Sci 2013; 4 (4): 2530-2534.

15. Pontarolo R, Gimenez AC, de Francisco TMG, Ribeiro $R P$, Pontes FLD, Gasparetto JC. Simultaneous determination of metformin and vildagliptin in human plasma by a HILIC-MS/MS method. J Chromatogr B 2014; 965: 133-141.

16. Al Bratty M, Alhazmi HA, Sadique AJ, Lalitha KG, Asmari M, Wolker J, El Deeb S. Development and validation of LC-MS/MS method for simultaneous determination of metformin and four gliptins in human plasma. Chromatographia 2017; 80: 891-899

17. Abdel-Ghany MF, Abdel-Aziz O, Ayad MF, Tadros MM. Validation of different spectrophotometric methods for determination of vildagliptin and metformin in binary mixture. Spectrochim Acta A Mol Biomol Spectrosc 2014; 125: 175-182

18. Younes OM, Al- Zehouri J, Abboud $H$. Spectrophotometric Method for the Determination of Vildagliptin in Bulk and Pharmaceutical Dosage Forms, Int J Pharm Sci Rev Res 2014; 29 (1): 33-36

19. Raveendra BG, Vijay KG, Kalyani M, Roshna Md, Jeevana $R$, Vijay $K$, Ajay $S$. stability-indicating simultaneous estimation of vildagliptin and mirabegron in bulk and pharmaceutical dosage form by using UV spectroscopy. World J Pharm Pharm Sci 2017; 6 (5): 912-925

Trop J Pharm Res, September 2018; 17(9): 1851 
20. Banik S, Karmakar P, Miah Md. Development and Validation of a UV-Spectrophotometric Method for Determination of Vildagliptin and Linagliptin in Bulk and Pharmaceutical Dosage Forms. Bangladesh Pharm J 2015; 18 (2): 163-168.
21. Marwa SM. LC-UV determination of Vildagliptin either alone or simultaneously with metformin in pharmaceutical preparations. Bulletin of Faculty of Pharmacy, Cairo University 2013; 51: 139-150. 